Nicole Burzan

Zeitgestaltung im Alltag älterer Menschen 
Forschung

Soziologie

Band 173 
Nicole Burzan

\section{Zeitgestaltung im Alltag älterer Menschen}

Eine Untersuchung im Zusammenhang mit Biographie und sozialer Ungleichheit

Springer Fachmedien Wiesbaden GmbH 2002 
Dissertation im Fach Soziologie an der FernUniversität Hagen unter der Betreuung von Prof. Dr. Werner Fuchs-Heinritz

Gedruckt auf säurefreiem und alterungsbeständigem Papier.

Die Deutsche Bibliothek - CIP-Einheitsaufnahme

Ein Titeldatensatz für die Publikation ist bei Der Deutschen Bibliothek erhältlich

ISBN 978-3-8100-3684-1 ISBN 978-3-663-11902-9 (eBook)

DOI 10.1007/978-3-663-11902-9

\section{(C) 2002 Springer Fachmedien Wiesbaden}

Ursprünglich erschienen bei Leske + Buderich, Opladen 2002.

Das Werk einschließlich aller seiner Teile ist urheberrechtlich geschützt. Jede Verwertung auBerhalb der engen Grenzen des Urheberrechtsgesetzes ist ohne Zustimmung des Verlages unzulässig und strafbar. Das gilt insbesondere für Vervielfältigungen, Übersetzungen, Mikroverfilmungen und die Einspeicherung und Verarbeitung in elektronischen Systemen.

Umschlaggestaltung: disegno, Wuppertal 


\section{Inhalt}

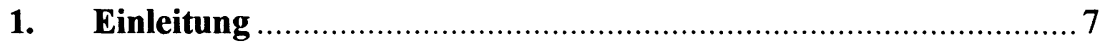

2. Spezifika der Lebensphase ,Alter' als Basis für Zeitgestaltung ... 11

2.1 Historische Betrachtung des Alters............................................. 12

2.2 Die Lebensphase Alter: Begriffsklärung ....................................... 16

2.3 Der demographische und soziostrukturelle Wandel des Alters......... 18

2.4 Die Lebenslage im Alter................................................................. 25

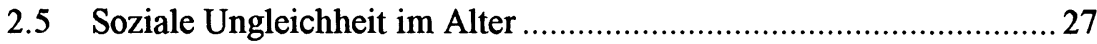

2.6 Lebensstile und andere Typologien älterer Menschen .................... 32

3. Zeitsoziologische Verknüpfungen ............................................ 43

3.1 Zeit als soziales Konstrukt und Ordnungsfaktor .......................... 43

3.1.1 Historischer Überblick und Kennzeichen von Zeit in der Moderne ... 47

3.1.2 Kulturvergleichende Forschung................................................. 52

3.1.3 Zeitdiskussion als Gesellschaftskritik ........................................ 54

3.2 Zeit und soziale Ungleichheit ........................................................57

3.2.1 Zeit und Sozialstruktur.................................................................58

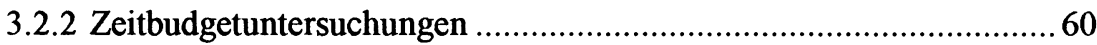

3.2.3 Arbeitszeit und Freizeit in der modernen Gesellschaft.....................61

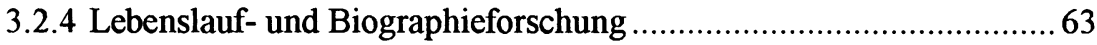

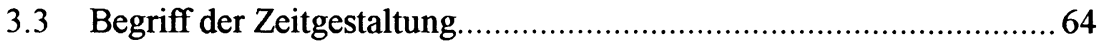

3.4 Bedeutung des Themas Zeitgestaltung für Rentnerinnen und Rentner - die Fragestellung der Arbeit .........................................65

4. Zeitgestaltung in empirischen Studien .................................. 71

4.1 Zeit im Alter: Zeitverwendung, Zeitperspektive und Zeitgestaltung.. 71

4.1.1 Zeitverwendung im Alter ........................................................ 71

4.1.2 Die Zeitperspektive und die Lebenszeit älterer Menschen............... 80

4.2 Zeitgestaltung anderer Bevölkerungsgruppen ................................89

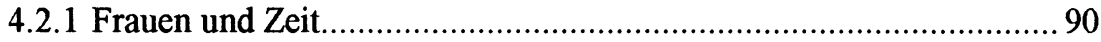

4.2.2 Zeit von Kindern und Jugendlichen............................................ 95

4.2.3 Arbeitslose und Zeit ............................................................ 100 
5. Das methodische Vorgehen dieser Untersuchung .................... 105

6. Muster der gegenwärtigen Zeitgestaltung im Alltag................. 115

6.1 Konstruktion des Musters........................................................... 116

6.2 Einordnung in das Muster: Typenbildung .................................. 118

6.3 Weitere Gemeinsamkeiten der Fälle in den Mustern...................... 120

6.4 Die subjektiven Deutungen........................................................... 127

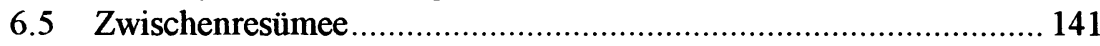

7. Der Zusammenhang zwischen Biographie und heutiger Zeitgestaltung im Alltag......................................................... 147

7.1 Biographische Typen nach zentralen Lebensbereichen .................. 147

7.2 Zusammenhänge der biographischen Typen zur Zeitgestaltung im

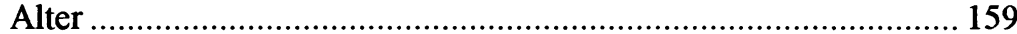

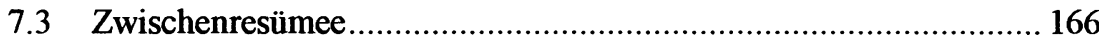

7.4 Hypothesen über mögliche Typenwechsel innerhalb der

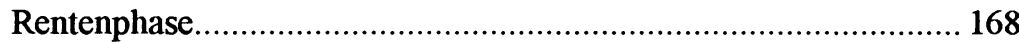

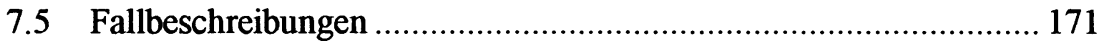

8. Zeitgestaltung im Alter und soziale Ungleichheit.................... 183

9. Zusammenfassung und Ausblick.............................................. 193

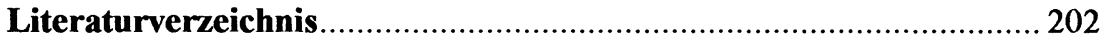

Verzeichnis der Tabellen und Abbildungen ................................... 220 